\title{
EDUCAÇÃO, MÍDIAS E TIC: REFLEXÕES SOBRE O PAPEL DOCENTE*
}

\author{
FERNANDO TAVARES JR. \\ Universidade Federal de Juiz de Fora, Juiz de Fora, Minas Gerais, Brasil \\ ROBERTA SCOTON \\ Universidade Federal de Juiz de Fora, Juiz de Fora, Minas Gerais, Brasil
}

RESUMO: A difusão de novas tecnologias da informação e comunicação trazem aos processos sociais novas potencialidades, mas também novos desafios. Os funcionamentos em rede permitiram a emergência de uma nova comunidade epistemológica, de fato genuína em seus elementos e processos produtivos. Analisam-se implicações didáticas dessas transformações, tendo em vista a proposição de novos argumentos à discussão dos papéis e desafios à profissão docente e à escola, em função das transformações sociais e culturais típicas do advento da Sociedade da informação, cuja análise soma-se à dos atores e seus novos papéis e aos desafios apresentados à instituição escolar. Observou-se que não é a introdução de novas TICs que "moderniza" o processo educacional, mas uma nova concepção epistemológica, indutora de uma práxis educativa transformadora.

Palavras-chave: Educação. Mídias. Sociedade da informação. Tecnologias de Informação e Comunicação (TIC). Formação de professores.

\section{APRESENTAÇÃO ${ }^{1}$}

A produção e a difusão do conhecimento foram exponencialmente ampliadas nas últimas décadas, a partir do advento de novas plataformas tecnológias. Os microcomputadores pessoais e o acesso à internet estão ao alcance de largas camadas da população, gerando novos funcionamentos

\footnotetext{
* Artigo recebido em 20/2/2014 e aprovado em 5/5/2014.
} 
sociais. Tais transformações provocaram mudanças radicais no cotidiano das novas gerações e na maneira como se relacionam entre si, com o mundo e com o saber. No entanto, permanece sendo estrutural e culturamente a mesma sociedade, que cada vez mais se impõe e se utiliza de tais funcionamentos para reforçar seu modus operandi, com destaque para a educação.

As novas tecnologias não criaram uma nova sociedade, mas amplificaram as possibilidades do modo de produção vigente, expandindo fronteiras e, junto delas, impondo novos desafios. Diante das mudanças operadas pelo advento das novas tecnologias de comunicação e informação (TICs), surge consigo a necessidade crescente de se repensar o papel da escola e dos professores. O que se mostra novo é a repercussão das novas TICs na instituição escolar e como ela afeta a relação professor-aluno-saber. Mais do que uma reflexão teleológica sobre a educação contemporânea, impõe-se uma reflexão epistemológica e didática. O que é ser cidadão capaz de transitar com hábil consciência na sociedade contemporânea? Qual o significado de um diploma enquanto domínio de determinado conjunto de conteúdos e principalmente a capacidade de letramento pleno e de contínua aprendizagem em diferentes campos?

As novas TICs e sua difusão pelo globo aparecem em um determinado momento histórico que é denominado por diversos nomes como: a "Era Planetária", de Morin; a "Era da Informação" produzida pela "Sociedade em Rede", de Castells; ou a "Modernidade Líquida", de Bauman. Todas apresentam em comum as novas chaves analíticas para compreensão do contemporâneo. Berstein (1990a, 1990b) tem enfatizado desde o final do século XX a transição de uma sociedade baseada em recursos físicos (matérias-primas, força de trabalho, instalações etc.) para uma sociedade fundada em informação e conhecimento. Harvey (1994) procurou explicar como é que o acesso à informação e ao conhecimento científico e técnico assumiu uma centralidade renovada nos dias de hoje, sendo, inclusive, transformados em mercadorias (STOER; MAGALÃES, 2003). Nesta "sociedade técnico-informacional" ou "sociedade do conhecimento", há a centralidade do saber e da educação, os quais são também - e principalmente - "bens econômicos" necessários à produção, aumento do lucro e poder de competição (LIBÂNEO, 2009, p. 110).

Experimentamos nas últimas décadas transformações efetivas no modo de produção da vida que afetam toda a sociedade, suas instituições e suas relações. Para além da superação do modelo técnico gerencial fordista, a era digital trouxe consigo a Reestruturação Produtiva, com a alteração dos padrões técnicos, mas também das múltiplas organizações do trabalho e, principalmente, do papel do conhecimento no seio das relações de produção. Sinteticamente, tais teorias apontam a emergência de uma sociedade que 
se encontra imersa em uma revolução tecnológica, em que a comunicação, a informação e o conhecimento são elementos centrais.

A despeito de uma reflexão mais genérica, importa aqui refletir sobre as repercussões educacionais de tais mudanças. Para tanto, como provocação incipiente, relata-se o observado numa aula de História, lecionada em uma turma regular de Ensino Médio, em uma escola da rede estadual de ensino de Minas Gerais. O tema era: Iluminismo. Ao trabalhar com os alunos a compreensão do Enciclopedismo no século XVIII, além de citar o papel de Diderot e D'Alembert, a professora foi interpelada por um aluno: "Professora, então a Enciclopédia é o Google de antigamente?". Essa intervenção do aluno ocasionou uma grande e rica reviravolta no rumo da aula. A partir de então, a aula transformou-se numa reflexão acerca das mudanças na forma de assimilação dos conteúdos, a difusão da informação, da maneira de se ensinar, da imprensa, das várias mídias e pontos convergentes. Em seguida, os alunos relataram experiências de aprendizagem extraclasse sobre os conteúdos trabalhados em sala, como a elaboração de trabalhos através de informações obtidas em sites da internet (o que, para alguns professores, seria um dos efeitos prejudiciais do uso do computador pelos alunos) e, em tom de deboche, outro aluno relatou que, para estudar para a prova de recuperação do ano anterior, não recorreu ao livro didático, mas acessou vídeos no YouTube. O aluno obtivera êxito. Estava implícita a ideia de que a aprendizagem através dos vídeos fora mais eficiente que os livros e até as aulas.

Tais experiências nos remetem aos desafios que se colocam ao professor diante de novas configurações educacionais contemporâneas: o diálogo com as diferentes mídias em sala de aula, os conflitos com alunos a partir do "questionamento de sua autoridade", a forma dispersa com que os alunos lidam com as informações e conhecimentos e principalmente a reflexão sobre quem se deseja formar na educação básica e como fazê-lo.

Objetiva-se, a partir de uma reflexão baseada em um conjunto de pesquisas dedicadas ao tema, propor novos argumentos à discussão dos papéis e desafios à profissão docente e à instituição escolar, em função das transformações que são empreendidas nas relações sociais e culturais com o advento da sociedade da informação. A fim de elucidar essa questão, desenvolvemos o artigo a partir de três chaves principais. O primeiro momento delineará, de forma sintética, as principais características da sociedade da informação que afetam nosso objeto e as modificações que se colocam à educação, de maneira geral. O segundo momento refletirá sobre os atores envolvidos no processo de contínua construção da aprendizagem - professores e alunos -, enfatizando seus novos papéis enquanto sujeitos históricos, suas diferenças geracionais e as consequências dessa dialética para 
a reestruturação do processo didático. Por fim, serão debatidos os principais desafios apresentados à instituição escolar e aos docentes enquanto um novo horizonte reflexivo e uma agenda prospectiva de investigações educacionais.

\section{A EDUCAÇÃO NA ERA DA INFORMAÇÃO}

Neste artigo, opta-se pela categoria "Era da Informação", cunhada por M. Castells (1999), por expressar a importância e centralidade da informação em nossa sociedade e, principalmente, por articular com as categorias "informação" e "conhecimento" que se configuram enquanto elementos centrais no processo de ensino-aprendizagem. Esses elementos se modificaram de forma substancial na sociedade contemporânea, no que se refere principalmente a sua vinculação e apreensão, o que determina sobremaneira alterações no ambiente escolar, no papel dos agentes e no perfil dos alunos. Castells (1999) propõe novos conceitos para se compreender as tendências que caracterizam a estrutura e dinâmica das nossas sociedades do século XXI. Parte-se da "cultura da virtualidade real", definida como

redes digitalizadas de comunicação multimodal [que] passaram a incluir de tal maneira todas as expressões culturais e pessoais a ponto de terem transformado a virtualidade em uma dimensão fundamental da nossa realidade. (CASTELLS, 1999, p. XVI)

Diante dessa cultura da virtualidade real, surge uma nova concepção de "realidade", baseada na virtualidade e nas relações e empreendimentos de base imaterial, possibilitadas pelas tecnologias da informação e comunicação, notadamente a internet. Deriva-se uma reconfiguração decisiva das sociabilidades, das relações políticas, sociais, econômicas e culturais por todo o globo. Portanto, a cultura da virtualidade real é possibilitada pelos recursos de multimídia, através dos quais experimentamos a virtualidade do real, que é uma cultura sustentada na imagem e no espetáculo, que faz confundir a realidade com a ficção, e vice-versa (ABREU, 2006, p 163).

Segundo Mitchell (1995), estariam "emergindo on-line novas formas de sociabilidade e novas formas de vida urbana, adaptadas ao nosso novo meio ambiente tecnológico" (apud CASTELLS, 1999, p. 443). Weetheim (2000) resume as cinco características fundamentais do novo paradigma tecnológico, que foi apresentado por Castells: (1) informação é matéria-prima; (2) os efeitos das novas tecnologias têm alta penetrabilidade; (3) predomina-se a lógica de redes; (4) flexibilidade e (5) crescente convergência de tecnologias. Castells compara a revolução que deu origem à Era da Informação com a Revolução Industrial Inglesa no século XVII ao afirmar que a tecnologia de informação 
está para este novo contexto como as fontes de energia estavam para "as sucessivas revoluções industriais, da máquina a vapor à eletricidade, aos combustíveis fósseis e à energia nuclear" (CASTELLS, 2011, p. 31).

Essa nova configuração social estabeleceria, então, duas questões principais na relação com a educação: por um lado, discute-se a reconfiguração dos papéis dos sujeitos envolvidos na aprendizagem, a partir da qual o professor passaria a ser um mediador entre os alunos e os conhecimentos em contínua produção. Por outro lado, destaca-se a modificação no acesso às informações e seu volume. A escola e o professor deixariam de ser o centro institucional do saber. $\mathrm{O}$ novo elemento emerge da facilidade de acesso às informações e sua multiplicidade, sem questionamento de confiabilidade, fidedignidade ou mesmo veracidade. A quebra de "monopólio" da escola tradicional como lócus privilegiado de acesso ao saber afeta a aprendizagem desses alunos e sua relação com o que se entende como conhecimento necessário à cidadania.

Tais alunos, que são denominados de "nativos digitais", adaptam-se naturalmente a uma nova linguagem e forma de aprendizagem que ocorre no contato com a tecnologia, seja pela TV aberta ou paga (cabo), pela internet e por muitas outras mídias (livretos, CDs, DVDs, revistas etc.), a partir de diferentes tecnologias. Com isso, os alunos se habituam à comunicação e aprendizagem veloz e dinâmica, que explora os diversos sentidos, não ficando restrita à leitura e memorização, característica da educação tradicional. Impõese um duplo desafio: o primeiro é propriamente epistemológico, como lidar com essa nova forma de organização da informação. O segundo é geracional e metodológico: como lidar com diferentes veículos de informação (mídias) que são marcadamente típicos de cada geração - o que uma usa ou prefere é frontalmente preterido pela outra.

A questão da educação na atualidade não é algo que podemos definir de uma maneira homogênea. Deve-se também observar que nossa sociedade é muito plural, e ainda apresenta um dos maiores índices de desigualdade social e econômica do mundo, sendo um dos 12 países mais desiguais no ranking levantado pela Organização das Nações Unidas. Ainda assim, o Brasil e a América Latina estão se tornando cada vez mais urbanos e digitais. Para ilustrar, vale a pena analisar os dados sobre acesso à internet, a partir dos quais vemos que a desigualdade se reflete no acesso ao mundo digital: entre os $10 \%$ mais pobres, apenas $0,6 \%$ tem acesso à internet; entre os $10 \%$ mais ricos, esse número é de $56,3 \%$. Somente $13,3 \%$ dos negros usam a internet, mais de duas vezes menos que os de raça branca $(28,3 \%)$. Os índices de acesso à internet das Regiões Sul $(25,6 \%)$ e Sudeste $(26,6 \%)$ contrastam com os das Regiões Norte (12\%) e Nordeste (11,9\%). Entretanto, dados indicam o 
aumento substancial do número de internautas, como se pode ver na tabela abaixo, que indica o crescimento do número de computadores nas casas dos brasileiros, ao longo de alguns anos.

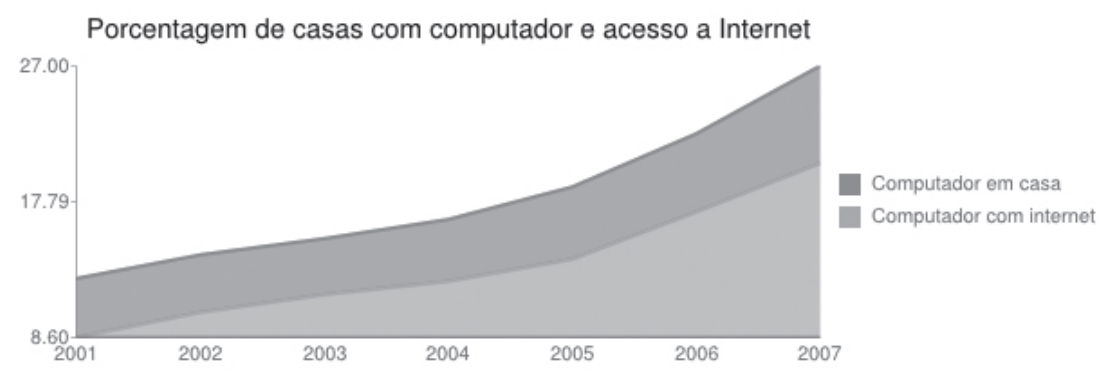

Segundo o lbope NetRatings, somos 79,9 milhões de internautas em nosso país, sendo o Brasil o $5^{\circ}$ país mais conectado. De acordo com a Fecomércio-RJ/Ipsos, o percentual de brasileiros conectados à internet aumentou de $27 \%$ para 48\%, entre 2007 e 2011 . O principal local de acesso é a lan house (31\%), seguido da própria casa (27\%) e da casa de parentes e amigos, com 25\% (abril/2010). Há 46,3 milhões de brasileiros que acessam regularmente a internet, $38 \%$ acessam a web diariamente; e $87 \%$ dos internautas brasileiros entram na internet semanalmente. $\mathrm{O}$ ritmo de crescimento da internet brasileira é intenso. A "expansão da classe C" deve continuar a manter esse mesmo compasso forte de aumento no número de usuários residenciais.

\section{OS SUJEITOS DA APRENDIZAGEM: PROFESSORES E ALUNOS}

Os alunos de nossas escolas atuais, identificados enquanto "Nativos Digitais", o são assim designados porque "passaram etapas importantes do seu desenvolvimento cognitivo imersos na realidade virtual, proporcionada por internet, games, SMS, computador, MSN entre outros" (BISPO \& SEPINI, 2011, p. 2). A maneira de estruturarem o pensamento, valores, o formato de busca de informações, o conceito de entretenimento, os hábitos de consumo e a percepção do mundo desta geração são diferentes da maneira de ver, sentir, estar e interagir no mundo das gerações anteriores. Diversos estudos buscam entender esta geração a partir três categorizações principais.

A primeira seria a Baby Boomer, nascidos entre o pós-Grande Guerra e os anos de 1960, criados no auge da Guerra Fria e em um contexto de emergência das classes médias e do Welfare State nos países desenvolvidos. É uma geração televisiva, mas ainda leitora de mídias clássicas e clientes do 
mercado editorial tradicional, como jornal, livros etc. A segunda é a Geração X, nascidos nos anos de 1970 e meados dos anos de 1980, cuja infância foi marcada pelo advento do video game, da expansão e quase universalização da TV (em cores). São em geral tidos como mais passivos e descrentes de mudanças que os jovens da geração anterior. A terceira é a Geração $Y$, atual, nascidos a partir de meados dos anos de 1980. A principal característica dessa geração é a relação que estabelecem com as novas mídias e "o que rege é a experiência on-line, fluida, hipermídia, sem raízes" (CARA, 2008). Essa geração nasceu já em contato com o computador pessoal, se não em casa, pelo menos em algum espaço social. Sempre foi "bombardeada" por muitas informações, o que, grande parte das vezes, tornou-se excesso de distração durante a adolescência. Não viveram conflitos ideológicos ou econômicos que marcaram gerações anteriores. Foram letrados no mundo digital e sempre apresentaram muita facilidade na incorporação de novas tecnologias.

Os indivíduos das gerações anteriores (Baby Boomer e Geração X) seriam os "imigrantes digitais", que não possuem familiaridade com novas tecnologias em função da não naturalidade com que conviveram com elas em sua socialização primária, como ocorreu com a geração dos nativos digitais. No entanto, também dialogam e procuram estar atualizados em relação às TICs, mesmo apresentando uma compreensão epistemológica de mundo profundamente distinta. Observa-se, portanto, a existência de gerações antagônicas em relação às TICs. Os professores seriam majoritariamente imigrantes digitais, e os alunos, nativos digitais. Uma geração prefere e elege o livro como principal fonte de saber. A outra o acha chato, entediante, estático. Uma geração tem maior clareza sobre fontes de conhecimento (em geral, em função de sua base científica) e fontes genéricas de informação (mais ligadas às notícias conjunturais). Outra tende a confundi-las e miscigenar conhecimento e informação, ambos classificados como transitórios. A dialética entre moderno e pós-moderno, entre ciência e mercado, entre verdade e verdades é também uma dialética entre gerações, reflete também uma dialética entre sujeitos em sala de aula, expressa-se na dialética da didática contemporânea.

Os professores que hoje estão, em média, na faixa etária dos 30 aos 50 anos enquadram-se em uma geração de "imigrantes digitais", que estão contemporaneamente aprendendo a lidar com a tecnologia. Ela já está presente em suas vidas por meio de diversas obrigações que hoje são basicamente virtuais, utilizando a internet, como a declaração do imposto de renda, a inscrição em concursos, o uso de redes sociais e e-mails, entre outros. Apesar de essa realidade já estar presente na sociedade e afetar a escola desde o final do século passado, ao analisarmos os cursos de formação de 
professores, verificamos as fragilidades de uma estrutura curricular que não privilegia a formação didática adequada aos desafios sociais contemporâneos, nem a inovação didática em sala de aula. Como, então, novos docentes estariam aptos a trabalhar com os"nativos digitais"? Identifica-se que o desafio aos professores é uma realidade imposta desde sua formação inicial, tendo-se em vista a atual estrutura das licenciaturas.

Portanto, identifica-se que o desafio aos professores é uma realidade imposta desde sua formação inicial, tendo-se em vista a atual estrutura das licenciaturas. Não se espanta observar de outro lado a relutância de muitos colegas docentes frente à inovação pedagógica e ao uso de tecnologias, mesmo depois de eventuais formações continuadas sobre o tema. Questiona-se até que ponto a dificuldade na inovação didática se insere em um contexto mais amplo de precarização da carreira docente e de sua formação.

Logo, questões se impõem: Como organizar didaticamente a construção do conhecimento na Era da Informação? O que é uma aula instigante a esses alunos familiarizados com a tecnologia? Como utilizar a tecnologia a favor do ensino reflexivo? Como estabelecer parcerias produtivas com a avalanche de informações às quais os alunos têm acesso fora da sala de aula? Qual a postura e o papel do professor nesse contexto educacional?

Tais questões se tornam ainda mais relevantes diante da discrepância crescente que se observa entre essas duas gerações. Nagoya (2012) disserta sobre as mudanças culturais e sociais que ocorreram nos últimos anos (a partir da década de 1990) com a utilização crescente de dispositivos virtuais e afirma que essa mudança na matriz cultural também modificou o comportamento das novas gerações. Sua hipótese baseia-se no argumento de Goffman (apud NAGOYA, 2012), segundo o qual "quem nasceu de 1980 para cá é um nativo digital, então lida com essas mídias de forma muito naturalizada, enquanto as pessoas que aprenderam a lidar com elas depois de alfabetizadas, os imigrantes digitais, têm mais cautela, tanto que são os jovens que introduzem tecnologia em casa". Goffman (apud NAGOYA, 2012) alerta, ainda, que o sistema educacional tem que levar em conta essa nova realidade e esse novo perfil de jovem:

As crianças hoje conseguem fazer mais coisas ao mesmo tempo e a escola precisa aproveitar isso no ensino. E isso confunde a sociedade, muitos dizem'essas crianças não conseguem prestar atenção em nada', quando na verdade elas prestam atenção em muitas coisas ao mesmo tempo. (NAGOYA, 2012, p. 10)

Essa discussão nos remete a um tema recorrente nas publicações recentes que analisam a educação na contemporaneidade, que destacam um novo perfil de aluno que chega às instituições de ensino regular, ou seja, quem 
é esse nativo digital que tem que passar pelo ensino regular? É recorrente a afirmação de que as escolas e seus professores estariam despreparados para receber esses novos alunos, que teriam outras demandas e estariam conectados aos"novos tempos", em que há a predominância de novas formas de sociabilidade e que a utilização de recursos tecnológicos no cotidiano seria naturalizada desde a mais tenra infância, como vimos anteriormente.

Além disso, observa-se, em diversas pesquisas sobre a educação contemporânea, um crescente questionamento dos elementos didáticos clássicos, nos quais tem se apoiado a prática docente nos últimos séculos. Mesmo o desenvolvimento de habilidades básicas, como a memorização, é frequentemente questionado, por exemplo, em função de os bancos de dados, sites e redes em nuvem apresentarem enorme capacidade de armazenamento e disponibilização de informações. Não se percebe que a vida não se esgota em frente a um PC e as interações sociais não podem depender exclusivamente do sinal de internet captado por seu smartphone ou tablete. Cada cidadão existe para além dessas tecnologias. Em síntese, não é a tecnologia que estabelece os horizontes e limites da vida, mas é a vida social quem estabelece os usos e limites da tecnologia.

Em defesa da primazia da vida, em especial da vida socialmente construída em torno da cultura, advoga-se um contra-argumento. A aprendizagem ideal não giraria em torno da seleção e do manejo das novas tecnologias e das nuvens de informação. A formação escolar contemporânea permanece sendo uma produção social, que refere seus objetivos, processos e valores à sociedade na qual se insere. Nessa inserção, incorpora novas TICs para ampliar suas possibilidades de melhor formação, não para se subsumir ao desenvolvimento tecnológico. Logo, seria moderna uma educação que incorpora novas TICs de forma original, autônoma e condutora de sua história, não um processo genérico de compra de microcomputadores e expedição de tarefas a serem executadas com auxílio da internet. Tais práticas heterônomas não agregariam em si novas possibilidades à formação humana, mas repetem processos tradicionais apenas usando instrumentos tecnologicamente mais avançados. Um texto não é melhor porque foi escrito num editor de texto em detrimento da máquina de escrever ou do lápis/caneta. Um texto é melhor porque é mais instigante, reflexivo, porque aponta novas interrogações e propõe novas ideias, não em função do instrumento usado para escrevê-lo. Essa metáfora pode se aplicar a vários contextos. Importa perceber seu cerne: o desafio didático não está nos instrumentos, mas nas possibilidades reflexivas advindas a partir desse novo padrão técnico.

Nesse sentido, o papel do professor no processo de aprendizagem foi de fato modificado: passou a ser um organizador de processos cognitivos 
e não um detentor do saber que deve ser transmitido ao aluno. Como observamos, as fontes de informações estão disponíveis e em rede e podem ser acessadas por todos de forma exponencialmente facilitada. $O$ papel do professor como orientador passa a ser o mais destacado, na medida em que ele deve ensinar a pesquisar e selecionar informações, e lidar com elas, em grande quantidade.

Essa modificação se coloca também em um nível mais amplo, quando pensamos na função da escola nesta realidade. A formação ocorre em múltiplos espaços, para além da família e da escola, mas sem se desligar de sua posição de classe, "com base de recursos eventualmente menos sujeitos ao controle democrático e evidenciando dessa forma uma ativação considerável dos processos ligados à posse da capital cultural e social" (STOER \& MAGALHÃES, 2003, p. 1193).

\section{DESAFIOS À PROFISSÃO DOCENTE E INSTITUIÇÃO ESCOLAR}

Um desafio em relação à didática está na superação da aula centrada na transmissão de informações. Segundo Silva (2010), os professores estão acostumados com o que denomina de "paradigma da simplificação e a lógica da distribuição" e, com isso, a maioria deles não questiona a forma de ensino baseada na transmissão unilateral de conhecimentos aos alunos. $O$ melhor paradigma seria a "sala de aula interativa", em que o professor construiria um conjunto de territórios a serem explorados pelos alunos e tornaria factível a coautoria e as múltiplas conexões, permitindo que o aluno faça por si mesmo. Dessa maneira, a educação seria um processo de troca e de ações conjuntas que criariam conhecimentos e, de preferência, nunca os reproduziriam. $\mathrm{O}$ objetivo principal do autor com a defesa da sala de aula interativa é apontar perspectivas que possam contribuir para "inventar um novo modelo de educação", capaz de "disseminar um outro modo de pensamento" (SILVA, 2010, p. 28).

Marco Silva corrobora com a ideia de Pierre Levy (1999) quando este afirma que há a emergência de um novo leitor, que não se identifica apenas como receptor, mas interfere, manipula, modifica e anima, reinventa a mensagem. Os professores passam a ter que ficar atentos para um "novo estilo digital de apreensão dos conhecimentos", ou seja, para um novo comportamento e forma de aprendizagem "oriundo também da nova racionalidade técnica e dos estímulos perceptivos que ela engendra" (SILVA, 2010, p. 86). Há, sim, uma preocupação por alguns autores sobre as implicações da sociedade em rede para o desenvolvimento das capacidades individuais, notadamente em contextos educativos. 
É importante que essa introdução da tecnologia no contexto escolar não seja meramente instrumental, ou seja, ela deve vir junto com uma nova perspectiva didática que seja diferente da educação tradicional centrada na autoridade do professor e sua figura como foco de atenção exclusiva. Esse elemento relaciona-se diretamente com a incorporação de recursos à sala de aula, como computadores ligados à internet, dispositivos móveis, entre outros recursos, mas não de forma meramente instrumental. Importa perceber nesses recursos a manifestação de um salto qualitativo em relação à sala de aula tradicional. Representa usar tais instrumentos como desafios aos alunos.

Esses alunos têm, muitas vezes em sua própria residência, o contato com o computador. Através dos computadores e da conexão com a internet, houve uma modificação na forma de interação com as informações, com o conhecimento e com as outras pessoas que é bem diferente da que ocorria em outros meios, como a máquina de escrever, o retroprojetor. A diferença entre esses meios tecnológicos é a de que, na internet, a ação do sujeito se faz de forma interativa e utiliza diversos canais sensoriais, como a visão, o som, o movimento etc.

Essa interatividade, que é característica da comunicação via internet, segundo Silva (2010), inaugura uma nova modalidade comunicacional, que se contrapõe ao paradigma da transmissão que predomina nas escolas. A modalidade comunicacional baseada na interatividade exige "uma nova relação professor-aluno centrada no diálogo, na ação compartilhada, na aprendizagem colaborativa na qual o professor é um mediador" (SILVA, 2010, p. 86) que coordena equipes, provoca interrogações e orienta os alunos em pesquisas.

Do professor, passa a ser exigida a relação com a tecnologia, seja a busca de informações na rede, seja a utilização de meios tecnológicos nas atividades em sala de aula e fora dela, como a utilização de blogs, pesquisas em casa etc. Há, portanto, uma exigência em manter-se atualizado em relação ao conhecimento e também à tecnologia para acompanharem o ritmo dos alunos. Como afirma Abreu, "não basta mais recorrer somente às antigas fontes (livros, materiais didáticos, jornais, revistas etc.), há que ser usuário sistemático da rede" (ABREU, 2006, p. 177).

Em termos práticos, a conexão da escola à rede mundial de computadores permite o desenvolvimento de diferentes atividades: a) busca ágil de informações (pesquisa escolar, visitas a museus e outros lugares, visitas a sites interativos, artes plásticas, música, literatura, cursos virtuais); b) interações com pessoas (fóruns e listas de discussão, comunidades virtuais, chats, e-mails); c) entretenimento (jogos simulações). Todos esses recursos 
encontram-se disponíveis na internet e esta está presente no cotidiano da maioria dos alunos.

Moreira e Kramer (2007) afirmam que as próprias propostas curriculares têm apresentado radicalizações polarizadas no posicionamento em relação ao uso das tecnologias na escola: "ora vista como capaz de agravar os problemas da escola, ora como capaz de resolver os males educacionais" (MOREIRA, 2007, p. 1054). Abreu (2006) destaca essa polarização sobre a influência na tecnologia nas instituições de ensino ao afirmar que "correntes a favor (RAMAL, 2002; SILVA, 2000; VALENTE, 1999 etc.) teceram argumentos para proclamar as beneses do uso pedagógico da internet, enquanto a corrente contrária (SILVEIRA, 2001; CALLIGARIS, 1999 e outros) buscou advertir contra os 'perigos"' (ABREU, 2006, p. 165). Além disso, vemos uma positiva tendência crescente a se extrapolar as fronteiras da sala de aula enquanto lócus exclusivo de aprendizagem regular, como quando professores buscam diálogo e atividades didáticas complementares através da utilização de espaços virtuais com os alunos, como blogs, redes sociais etc.

Segundo Gadotti (2000), na transição das últimas décadas observou-se o predomínio da linguagem da televisão e da informática, principalmente da internet, enquanto a educação permaneceu operando quase exclusivamente na linguagem livresca, escrita: "os sistemas educacionais ainda não conseguiram avaliar suficientemente o impacto da comunicação audiovisual e da informática, seja para informar, seja para bitolar ou controlar as mentes" (GADOTTI, 2000, p. 5). Entretanto, o autor afirma que as novas tecnologias criaram novos espaços do conhecimento que extrapolam os muros da escola, estando presente também na empresa, no espaço domiciliar, no espaço social de maneira geral, que se tornam fontes potenciais de conhecimentos e informações:"cada dia mais pessoas estudam em casa, pois podem, de casa, acessar o ciberespaço da formação e da aprendizagem a distância, buscar 'fora' serviços que respondem as suas demandas de conhecimento' (GADOTTI, 2000, p. 7).

No contexto da sociedade informacional, a escola pode assumir posições estratégicas, organizando, em torno da produção cultural da cidadania, a imensa gama de informações disponibilizadas através das múltiplas mídias. Logo, a escola não se subordina às tempestades de informação cotidianas, mas é convidada a desempenhar papel autônomo e reflexivo sobre a sociedade na qual se insere.

Deve-se destacar, como característica da sociedade contemporânea, o surgimento de novas formas de sociabilidade e novas maneiras de se relacionar com o conhecimento e as informações. Esses aspectos exigem a produção, por nós, professores, de uma nova didática, que contemple a 
produção de conhecimentos em rede, que esteja baseada na interação, na cooperação e no trabalho colaborativo.

Em decorrência dos dois elementos destacados anteriormente sobre a influência das TICs para a instituição escolar e a profissão docente, é importante ressaltar alguns desafios. Aqueles formados em uma educação tradicional e que cresceram em um contexto em que a tecnologia não fazia parte do cotidiano, chamados de imigrantes digitais, são em geral identificados com o docente médio. Em contraponto, os alunos já seriam nativos digitais, por serem pessoas familiarizadas desde jovens com as tecnologias e informações vinculadas em rede.

Grande parte dos professores ainda tem como prática cristalizada um ensino tradicional baseado na transmissão de conteúdos e em aulas expositivas. Muitos desses professores, como estudos empíricos indicam, veem as TICs e a reconfiguração dos papéis dos agentes envolvidos no ensino como uma ameaça a sua posição enquanto autoridade detentora de conhecimentos, que por muito tempo predominou no ensino tradicional. No entanto, o que se observa é a crescente importância do professor no processo de informatização das escolas, na implementação de atividades pedagógicas apoiadas pelas novas tecnologias da informação e comunicação e na aplicação da internet como recurso definitivo. Abreu (2006) afirma que "estes trabalhos reclamam uma postura inovadora destes profissionais, colocando-os como agentes de mudanças educacionais. E os professores, como eles estão percebendo tudo isso? Como estão se sentindo? Como estão agindo?" (ABREU, 2006, p. 166).

A partir de larga pesquisa empírica com base em entrevistas com professores do ensino básico, Abreu (2006) observa que os professores relatam duas realidades que estão incomodando-os profundamente: a inversão na hierarquia do saber e os novos comportamentos dos alunos, os quais estão deixando os professores desorientados. Segundo esses professores, esses elementos levam a um desinteresse dos alunos pelas aulas convencionais, as aulas de 'cuspe e giz, expositivas, conteudistas', desconectadas do mundo dos alunos.

De maneira geral, observa-se que o cotidiano escolar foi afetado principalmente na redefinição do que se entende como"saber" ou "conhecimento", e em que medida isso opera como "estatuto de verdade". O cerne do fazer educacional permanece o mesmo: organizar experiências cognitivo-sociais que conduzam à aprendizagem do que é ser cidadão naquela sociedade. A Sociedade em Rede ampliou o acesso à informação, não necessariamente à aprendizagem ou à formação. Entre a informação e o conhecimento, há múltiplas distinções. Entre o conhecimento e a aprendizagem, há um extenso e 
complexo processo sócio-cognitivo. Da aprendizagem ao desenvolvimento de habilidades e competências, há também um percurso nem sempre simples.

Por fim, fazer de um sujeito competente também um cidadão pleno é tarefa social das mais relevantes. Logo, entre a ampliação do acesso à informação, a produção do conhecimento e a formação de cidadãos plenos, há um longo trajeto. É preciso ter muita atenção aos processos educacionais/ pedagógicos necessários e adequados a sua realização.

Com o advento da internet, os professores reveem os conceitos de informação e conhecimento, repensando suas práticas e, principalmente, alterando a própria concepção do magistério, que mais se aproxima de "animador da inteligência coletiva dos grupos". Isso leva a enormes transformações didáticas. A incorporação da internet ao cotidiano escolar leva a possibilidade de uso como plataforma permanente de aprendizado. Ao incorporar a internet ao cotidiano escolar, um primeiro estágio parece ter sido do uso da grande rede para trocas de experiências e preparação das aulas, uma atividade eminentemente didática. Embora os recursos elementares sejam, essencialmente, os mesmos, a forma de operá-los torna-se diferente, uma vez que são oferecidos subsídios variados para o planejamento da atividade docente.

Diante desse contexto, cabe à instituição escolar repensar sua estrutura curricular, organizacional e espacial para atender a essas novas demandas que surgem da sociedade e dos jovens. Entretanto, é importante que a integração do computador e da internet na escola seja acompanhada de uma reorganização escolar, tornando-a mais descentrada, com um currículo mais flexível, com a instauração de novos tempos escolares, menos rígidos e programados, e com mudanças no próprio espaço da sala de aula.

Como aponta Freitas (2006), essas mudanças demandam um longo processo de adaptação da escola, tanto em termos de estrutura como dos sujeitos envolvidos, notadamente os professores. Tem que se levar em consideração que a escola, pela primeira vez em sua história, não está isolada; ela pode estar conectada a outros centros, outras fontes de informação que estão além das paredes da sala de aula, dos livros, dos textos. Isso tudo leva a uma alteração da vida escolar que, entretanto, faz-se de forma muito lenta, pois a cultura escolar, presa em seus ritos e posicionamentos seculares de autoridade, tem dificuldades de se adaptar e acolher o novo. E essa resistência é muito forte, principalmente em relação à internet, que, embora esteja presente na maioria das escolas, é subaproveitada.

Além disso, no que se refere à formação inicial e continuada dos professores, seria positiva a introdução de outros elementos para que essa 
formação esteja em consonância com a nova configuração social típica da contemporaneidade: os professores devem ser preparados para utilizar as tecnologias muito precocemente em sua formação docente e, além disso, deve-se priorizar um novo perfil didático-metodológico durante a formação de professores, que valorize elementos como a colaboração e a construção coletiva de conhecimentos.

Éfundamental que essas mudanças ocorram nos Institutos Superiores de Educação, nas Faculdades de Educação, nos cursos de licenciatura, desde as primeiras disciplinas. Quem forma o professor deve questionar suas práticas e refletir melhor sobre a Educação Básica no Brasil. É importante levarmos em conta que os autores que se debruçam sobre o tema da educação na contemporaneidade - independentemente de analisar a relação TICs e sua utilização nas aulas ou a nova reconfiguração de papéis dos agentes envolvidos - tendem a concordar num crescente consenso acerca da importância da prática didática reflexiva, muito mais do que a defesa da simples incorporação de tecnologia.

\section{CONSIDERAÇÕES FINAIS}

Diante desses questionamentos, acredita-se que, fundamentalmente, o papel do professor permanece central na organização e produção do conhecimento, na realização da aprendizagem, na atuação enquanto "um agente altamente estratégico na cultura humana" (FELIX \& BARBOSA, 2011, p. 3). Seu papel é ainda mais decisivo e estratégico no mundo de hoje, em que há o acesso facilitado às informações, já que deve auxiliar o educando a aprender a selecionar e planejar melhor suas alternativas e recursos de acesso ao mundo da informação.

Como vimos, a difusão massiva de informações através de diversos suportes produz questionamentos à aula tradicional, focada na disponibilização de informações, na transmissão de conteúdos. Tais informações estão disponíveis também em outros meios. É preciso mais. É possível ao professor se mobilizar para empreender novas buscas e novos aprendizados, com o intuito de realizar um novo fazer pedagógico. É possível produzir uma nova relação com a tecnologia. Como afirma Abreu, "não basta mais recorrer somente às antigas fontes (livros, materiais didáticos, jornais, revistas etc.), há que ser usuário sistemático da rede" (ABREU, 2006, p. 177).

É a sociedade que demanda reflexões sobre como deve ser a adequada formação de cidadãos plenos, preparados para a inserção no mundo do trabalho cada vez mais tecnológico. As relações sociais baseadas também no universo virtual, nas redes sociais e nos contatos a distância, nas 
relações políticas globais, na pluralidade e no multiculturalismo, carecem de um contraponto à vulgarização do saber em tempestades de informações. A escola permanece lócus privilegiado do conhecimento, de produção de saber, de organização da vida social em latência, da aprendizagem. Pode-se avançar sem medo em direção à inclusão nesta realidade tal como ela se apresenta, e para a qual a escola não precisa ter receio de se desinsular, rumo a uma nova inserção epistelomógica na Sociedade do Conhecimento.

\section{EDUCATION, MEDIA AND ICT: REFLECTIONS ON THE ROLE OF TEACHING}

ABSTRACT: New media technologies have brought new potential to social processes but also new challenges. Networking has led to the emergence of a new epistemological community with genuine elements and productive processes. The didactic implications of these transformations are analyzed, bearing in mind the proposal of new arguments to discuss the roles and challenges to teaching and the school, because of the social and cultural transformations typical of the emergence of the information society, whose analysis is added to that of the actors and their new roles and challenges presented to the school institution. It is seen that it is not the new ICTs which "modernize" education but rather a new epistemological concept, which leads to transformative educational praxis.

Key words: Education. Media. Information society. Information and Communication Technologies (ICT). Teacher formation \& training.

EDUCACIÓN, MEDIOS DE COMUNICACIÓNY LASTIC: REFLEXIONES SOBRE EL PAPEL DOCENTE

RESUMEN: La difusión de las nuevas tecnologías de la información y comunicación trae a los procesos sociales nuevas potencialidades, pero también nuevos retos. Los funcionamientos en red permitieron el surgimiento de una nueva comunidad epistémica, de hecho genuina en sus elementos y procesos de producción. Se analizan las implicaciones didácticas de estos cambios, con el fin de proponer nuevos argumentos a la discusión de los papeles y desafíos para la profesión docente y para la escuela, basados en las transformaciones sociales y culturales típicas de la llegada de la Sociedad de la Información, cuyo análisis se suma a la de los actores y sus nuevos papeles y desafíos presentados a la institución escolar. Se observó que no es la introducción de las nuevas TICs que "moderniza" el proceso educacional, sino una nueva concepción epistemológica inductora de una práxis educativa transformadora.

Palabras claves: Educación. Medios de comunicación. La Sociedad de la Información. Tecnologías de la Información y de la Comunicación (TIC). Formación del profesorado. 
NOTA

1. O presente trabalho foi realizado com apoio do Programa Observatório da Educação, da Coordenação de Aperfeiçoamento de Pessoal de Nível Superior - Capes/Brasil.

\section{REFERÊNCIAS}

ABREU, R. “Cabeças digitais": um motivo para revisões na prática docente. In: NICOLACI-DA-COSTA, A. M. (Org.). Cabeças digitais: o cotidiano na era da informação. Rio de Janeiro: Ed. PUC-Rio; São Paulo: Loyola, 2006.

BERNSTEIN, B. Class and pedagogies: visible and invisible. 4. ed. London: Routledge, 1990a.

. The structuring of pedagogic discourse. Londres: Routledge, 1990b.

BISPO FILHO, D.; SEPINI, R.; MACIEL, M. Nativos digitais e a mediação didática pedagógica em Ambientes Virtuais de Aprendizagem (AVA): experiência vivenciada em aulas de ciências. IV Simpósio Nacional de Tecnologia e Sociedade, UTFPR Curitiba, 2011.

CARA, M. Gerações juvenis e a moda: das subculturas à materialização da imagem virtual. Modapalavra e-periódico, ano 1, n. 2, ago./dez. 2008.

CASTELLS, M. A sociedade em rede. São Paulo: Paz e Terra, [1999]2011.

FELIX, F.; BARBOSA, Z. Tecnologia na sociedade: estudo da concepção de adolescentes sobre o uso da Internet. IV Simpósio Nacional de Tecnologia e Sociedade, UTFPR Curitiba, 2011.

FREITAS, M. A Internet na escola: desafios para a formação de professores. In: NICOLACI-DA-COSTA, A. (Org.). Cabeças digitais: o cotidiano na era da informação. Rio de Janeiro: Editora PUC-Rio; São Paulo: Loyola, 2006.

GADOTTI, M. Perspectivas atuais da educação. São Paulo em Perspectiva, n. 14, v. 2, 2000.

HARVEY, David. Condição pós-moderna: uma pesquisa sobre as origens da mudança cultural. São Paulo: Edições Loyola, 1994.

LEVY, P. Cibercultura. São Paulo: Ed. 34, [1997]1999.

LIBÂNEO, J. et al. Educação escolar: políticas, estrutura e organização. São Paulo: Cortez, [2003]2009. p. 110.

MOREIRA, A. F. B.; KRAMER, S. Contemporaneidade, educação e tecnologia. Educação e Sociedade, v. 28, n. 100, Especial, p. 1037-1057, out. 2007.

NAGOYA, O. Desafios da comunicação e desafios culturais. Caros Amigos, Especial Males do Mundo Atual, jul. 2012.

LEVY, P. Cibercultura. São Paulo: Editora 34, 1999.

SILVA, M. Sala de aula interativa. 5. ed. São Paulo: Edições Loyola, 2010. 
STOER, S. R.; MAGALHÃES, A. Educação, conhecimento e sociedade em rede. Educação e Sociedade, Campinas, v. 24, n. 85, p. 1179-1202, dez. 2003.

WERTHEIN, J. A sociedade da informação e seus desafios. Ciência da Informação, v. 29, n. 2, p. 71-77, maio/ago. 2000.

Fernando Tavares JR. é professor adjunto do Departamento de Ciências Sociais, Instituto de Ciências Humanas/UFJF. É corpo permanente do Programa de Pós-Graduação em Ciências Sociais, PPGCSO/UFJF e do Programa de Pós-Graduação em Gestão e Avaliação da Educação Pública, PPGP/UFJF. É coordenador do Grupo de Pesquisa CNPq "Equidade, políticas e financiamento da educação pública" e também do Obeduc/Capes "Determinantes do sucesso educacional no Brasil" e coordenador CNPq "A produção da desigualdade educacional no Brasil".

E-mail: ftavares@caed.ufjf.br

ROBERTA SCOtOn é doutoranda em Ciências Sociais pela Universidade Federal de Juiz de Fora (UFJF), mestre em Ciência da Religião pela UFJF (2007) e graduada em História pela UFJF (2004). Atualmente, é professora de História do Governo do Estado de Minas Gerais e tutora na Faculdade de Educacão, UAB/UFJF, da Universidade Federal de Juiz de Fora. Tem experiência na área de Ciência da Informação, com ênfase em Organização de Arquivos, atuando principalmente nos seguintes temas: psiquiatria, religiões mediúnicas, Juiz de Fora, legitimação medicina e kardecismo.

E-mail: robertascoton@hotmail.com 